\title{
Decomposition of different crop straws and variation in straw-associated microbial communities in a peach orchard, China
}

\author{
ZHANG Hong ${ }^{1,2}$, CAO Yingfei ${ }^{1}$, LYU Jialong ${ }^{1,2^{*}}$ \\ ${ }^{1}$ College of Natural Resources and Environment, Northwest A\&F University/State Key Laboratory of Soil Erosion and \\ Dryland Farming on the Loess Plateau, Institute of Water and Soil Conservation, Chinese Academy of Science and Ministry \\ of Water Resources, Yangling 712100, China; \\ ${ }^{2}$ Key Laboratory of Plant Nutrition and the Agri-environment in Northwest China, Ministry of Agriculture, Yangling 712100, \\ China
}

\begin{abstract}
Crop residue is a major source of soil organic matter; therefore, application of crop straw to soil contributes to the sustainable development of organic agriculture. To better understand the transformation of crop straw in orchard soils, we investigated the relationship between the characteristics of straw decomposition and functional diversity of associated microbial communities in a long-term peach orchard, China. Mesh bags, each containing $30 \mathrm{~g}$ of corn or bean straw, were buried at a soil depth of $20 \mathrm{~cm}$ in a 12-year-old peach orchard for $360 \mathrm{~d}$ (October 2011-October 2012). Three treatments were applied, i.e., fresh corn straw, fresh corn straw with nitrogen fertilizer (urea, $10.34 \mathrm{~g} / \mathrm{kg}$ ), and fresh bean straw. Changes in straw residual rate, straw water content and soil conditions were monitored after treatment. The functional diversity of straw-associated microbial communities was analyzed by the Biolog-Eco microplate assay. During the decomposition process, straw residual rates did not vary considerably from $10 \mathrm{~d}(30.4 \%-45.4 \%)$ to $360 \mathrm{~d}(19.0 \%-30.3 \%)$. Irrespective of nitrogen addition, corn straw decomposed faster than bean straw. Corn straw with nitrogen fertilizer yielded the highest average well color development (AWCD) values (1.11-1.67), followed by corn straw (1.14-1.68) and bean straw (1.18-1.62). Although the AWCD values did not differ significantly among the three treatments, substantial differences occurred across various time periods of the decomposition process $(P<0.01)$. In terms of carbon source utilization, the dominant microbial groups fed mainly on saccharides. Hard-to-decompose substances gradually accumulated in the middle and late stages of straw decomposition. Of the six categories of carbon sources tested, the utilization rate of aromatics was the lowest with corn straw, whereas that of polymers was the lowest with bean straw. Among different treatments, straw residual rate was negatively correlated to soil available phosphorous, soil available potassium and soil temperature $(P<0.05)$, but not to soil water content. In some cases (corn straw with or without nitrogen fertilizer), straw residual rate was negatively correlated to straw water content, amino acid utilization and carboxylic acid utilization, and positively correlated with microbial species richness and evenness $(P<0.05)$. Microbial community associated with corn and bean straw decomposition in soil was respectively dominated by aromatic- and polymer-metabolizing groups during the middle and late stages of this process, which could reduce the stability of microbial community structure and decrease the rate of straw decomposition in the fruit tree orchard.
\end{abstract}

Keywords: Biolog-Eco microplate; nitrogen fertilizer; microbial community; organic agriculture; straw decomposition

\footnotetext{
${ }^{*}$ Corresponding author: LYU Jialong (E-mail: 1j11@nwafu.edu.cn)

Received 2020-01-30; revised 2020-10-16; accepted 2020-12-06

(C) Xinjiang Institute of Ecology and Geography, Chinese Academy of Sciences, Science Press and Springer-Verlag GmbH Germany, part of Springer Nature 2021
} 
Citation: ZHANG Hong, CAO Yingfei, LYU Jialong. 2021. Decomposition of different crop straws and variation in straw-associated microbial communities in a peach orchard, China. Journal of Arid Land, 13(2): 152-164. https://doi.org/10.1007/s40333-021-0001-9

\section{Introduction}

Crop residue is a natural resource rich in nitrogen, phosphorus, potassium and many other elements necessary for plant growth. Application of crop straw to soil is therefore an effective way to improve soil quality and promote crop growth, which plays an essential role in the sustainable development of organic agriculture (Witt et al., 2000; Lao et al., 2003; Wu et al., 2014; Song et al., 2015). After its application, the decomposition of crop straw in soil is a complex process involving dynamic microbial activities. The rate of transformation of straw is related not only to the chemical composition of the straw but also to the environmental conditions of the soil (Wang et al., 2009; Han et al., 2016). In particular, soil water content is vital for the mineralization of plant residues, and there is an interactive effect between soil water and temperature on straw decomposition (Geisseler et al., 2011; Chen et al., 2012; Chen et al., 2014). Therefore, it is crucial to understand how different environmental factors affect the decomposition of crop straw for the rational utilization of agricultural resources.

Microorganisms as major drivers of nutrient biogeochemical cycles play a vital role in straw decomposition in soil. Previous studies have found that different straw properties and environmental factors can lead to substantial variation in the diversity of soil microbial communities (Feng et al., 2009; Merilä et al., 2010; Wang et al., 2012a). A common finding is that the presence of carbohydrates, urea and other small molecular organic compounds accelerates straw decomposition and transformation by substantially increasing the functional diversity of associated microorganisms (Tian et al., 2000; Ju et al., 2002; Hoyle et al., 2008; Jia et al., 2010). The ability of microorganisms to utilize single carbon sources in the Biolog-Eco microplate assay reflects the metabolic functions of microbial communities in the environment. Although traditional Biolog-Eco microplate assay cannot directly acquire detailed information on the microbial community structure (Wu et al., 2013), it provides a simple and rapid method for studying the metabolic activity and functional diversity of microbial communities ( $\mathrm{Lu}$ et al., 2013; Wang et al., 2016).

In China, many orchards have been established in arid and semi-arid barren hills with generally low content of soil organic matter and limited supply of water and fertilizer. Along with the development of organic cultivation of fruit trees, producers have paid increasing attention to scientifically-based planting strategies. Agronomic practices, such as straw application, are commonly used in orchard management to improve soil organic matter content and thereby soil quality (Sun et al., 2018). Straw application is the main way of adding exogenous carbon source to agricultural soils, and subsequent straw decomposition is a long-term process involving complex microbial communities (Pausch and Kuzyakov, 2012). Several studies showed that soil quality was improved after application of plant-derived organic fertilizers, while fruit yield and quality were also increased (Liu et al., 2008; Cheng et al., 2014). So far, many researchers have investigated the effects of climate condition, water availability, fertilizer application and straw chemical composition on soil microbial metabolic characteristics (Liu et al., 2014; Cao et al., 2015; Chen et al., 2015) for dry straws (Chen et al., 2014; Li et al., 2018, 2019). However, there is still limited information on the mechanisms underpinning microbially-mediated decomposition of fresh crop straw in orchard soils, especially the response of soil microbial functional diversity.

In this study, we conducted a field experiment in a long-term peach orchard using fresh corn straw and bean straw differing in their physical structure and chemical composition. We investigated the changes in functional diversity of microbial communities associated with the decomposition of corn straw and bean straw after their application to soil for one year based on the Biolog-Eco microplate assay. We also measured physical and chemical properties of straw and soil to examine their relationships with microbial activity and diversity. The results provide 
support data for maximizing the benefits of straw application and developing soil management strategies suited to environmental conditions in orchards, which could sustainably improve their soil fertility.

\section{Materials and methods}

\subsection{Study area and materials}

The study was carried out in a 12-year-old peach (Amygdalus persica L.) orchard, located within an experimental site of the Northwest A\&F University, Yangling, Shaanxi Province, China $\left(34^{\circ} 29^{\prime} 81^{\prime \prime} \mathrm{N}, 108^{\circ} 07^{\prime} 11^{\prime \prime} \mathrm{E}\right)$. The study area has an elevation of $525 \mathrm{~m}$, with an annual mean temperature of $13^{\circ} \mathrm{C}$ and an annual accumulated temperature $\left(\geq 10^{\circ} \mathrm{C}\right)$ of $4196^{\circ} \mathrm{C}$. The annual mean precipitation ranges from 550 to $600 \mathrm{~mm}$ and mainly occurs from July to September. Evaporation averages $993 \mathrm{~mm}$ per year, with a frost-free period of 184-216 d. The peach orchard was covered with grass mulch. The soil type is Lou soil and is classified as Earth-cumuli-Orthic Anthrosols in the Chinese Soil Taxonomy (Chang et al., 2001). The physical and chemical properties of the surface soil $(0-20 \mathrm{~cm}$ depth) before the experiment were as follows: $\mathrm{pH}, 8.2$; organic matter, $40.6 \mathrm{mg} / \mathrm{kg}$; available nitrogen, $64.8 \mathrm{mg} / \mathrm{kg}$; available phosphorus, $43.0 \mathrm{mg} / \mathrm{kg}$; and available potassium, $269.9 \mathrm{mg} / \mathrm{kg}$.

Corn (Zea mays L.) straw was collected from cropland in the experimental site, while bean (Glycine max (L.) Merr.) straw was collected from adjacent cropland. Fresh moist straws were crushed into 1-2 cm lengths and immediately stored in a refrigerator at $4^{\circ} \mathrm{C}$. The corn straw contained $402.48 \mathrm{~g} / \mathrm{kg}$ of total carbon and $11.31 \mathrm{~g} / \mathrm{kg}$ of total nitrogen, with a $\mathrm{C} / \mathrm{N}$ ratio of 35.59 . The bean straw contained $373.18 \mathrm{~g} / \mathrm{kg}$ of total carbon and $25.47 \mathrm{~g} / \mathrm{kg}$ of total nitrogen, with a C/N ratio of 14.65 .

\subsection{Experimental design and sampling}

The decomposition of fresh crop straws in soil was determined using mesh bags over a 360-d period between October 30, 2011 and October 30, 2012 (Guo et al., 2006). The optimal C/N ratio for the decomposition of organic matter by soil microorganisms is $25: 1$, whereas the $\mathrm{C} / \mathrm{N}$ ratio of plant residues, such as corn straw, is generally $>25: 1$ (Baumann et al., 2009; Wang et al., 2012a). In this case, nitrogen fertilizer could alter the soil microbial communities involved in straw decomposition. Herein, fresh corn straw was supplemented with nitrogen in the form of urea $(10.34 \mathrm{~g} / \mathrm{kg})$ to obtain a $\mathrm{C} / \mathrm{N}$ ratio of $25: 1$. Accordingly, a total of three straw treatments were applied, i.e., fresh corn straw (FC), fresh corn straw+nitrogen fertilizer (FCN), and fresh bean straw (FB). Thirty grams of fresh straw was packed into a double-layered nylon net bag (18 $\mathrm{cm} \times 12 \mathrm{~cm}, 350 \mathrm{mesh})$. Three pairs of peach trees were selected in two adjacent rows. The bags were buried in the soil at a depth of $20 \mathrm{~cm}$ and a spacing of approximately $2 \mathrm{~cm}$ between the paired trees. There were 90 bags per treatment and 270 bags in total.

Replicate straw samples were collected at 15 time points corresponding to 10, 20, 30, 45, 60, $90,120,150,180,210,240,270,300,330$ and $360 \mathrm{~d}$ of decomposition. For each sampling time, six bags per treatment were taken at random. Each of the bags was packed and returned to the laboratory, where all samples were immediately stored at $4^{\circ} \mathrm{C}$. Three bags of straw samples were used to determine the mass and water content, and the remaining three bags were used for microbial analysis. To avoid the influence of irrigation and rainfall, we weighed fresh straw samples after drying them at $60^{\circ} \mathrm{C}$ to a constant weight. Before burying the mesh bags, we manually collected soil samples between the paired trees at a depth of $0-20 \mathrm{~cm}$. Five soil samples were taken in an S-shaped pattern and mixed to form one composite sample for the determination of soil properties. After different time periods of straw decomposition, soil samples were collected in the same way and a total of 15 composite samples were obtained for the analyses of water content and microbial characteristics. A soil temperature logger (HOBO TidbiT v2, Onset Computer Corp., Bourne, USA) was buried at the $20 \mathrm{~cm}$ depth to record soil temperature hourly. 
We calculated the residual rate of crop straws during decomposition using the following equation: straw residual rate $(\%)=X_{t} / X_{0} \times 100 \%$, where $X_{0}(\mathrm{~g})$ is the initial mass of straw before decomposition; and $X_{t}(\mathrm{~g})$ is the residual mass during decomposition at time $t$. A higher residual rate indicates a lower decomposition rate of straw. We analyzed the physical and chemical properties of soil and straw samples using conventional testing methods (Bao, 2000).

\subsection{Microbial analysis}

The metabolic diversity of straw-associated microbial communities was measured by the Biolog-Eco microplate assay. The Biolog-Eco microplate assay comprised 96 wells containing 31 carbon sources that were classified into six categories with three controlled wells not adding carbon source. Triplicate straw samples ( $0.1 \mathrm{~g}$ dry weight) were dissolved in $49.9 \mathrm{~mL}$ of sterile $0.85 \% \mathrm{NaCl}$ solution and shaken at $180 \mathrm{r} / \mathrm{min}$ for $30 \mathrm{~min}$. Then the solution was centrifuged for 1 $\mathrm{min}$ at a speed of $3290 \mathrm{r} / \mathrm{min}$. A $1-\mathrm{mL}$ aliquot of the supernatant was diluted 10-fold using a sterile $0.85 \% \mathrm{NaCl}$ solution. Subsequently, $150 \mu \mathrm{L}$ of the diluted supernatant was inoculated into the Biolog-Eco microplate and incubated at $25^{\circ} \mathrm{C}$ for $6 \mathrm{~d}$ (Wang et al., 2012b). We measured carbon source utilization daily by measuring the absorbance at $590 \mathrm{~nm}$ using the Biolog Microstation ${ }^{\mathrm{TM}}$ System (BIO-TEK Instruments Inc., Winooski, USA) according to the manufacturer's instructions (Qian et al., 2014).

Average well color development (AWCD) value and diversity indices reflect the overall microbial community characteristics, whereas carbon source utilization indicates the predominant microbial metabolic functions. AWCD is calculated by the following equation: $\mathrm{AWCD}=\sum\left(C_{i}-R\right) / 31$, where $C_{i}$ is the absorbance of carbon source well; and $R$ is the absorbance of control well. Higher AWCD values indicate a higher microbial metabolic activity in terms of sole-carbon-source utilization (Zabinski and Gannon, 1997). Given that $144 \mathrm{~h}$ is the inflection time point of AWCD curve (Jia et al., 2013), we collected the data at $144 \mathrm{~h}$ to estimate the microbial diversity. Shannon's diversity index $(H)$, Simpson's diversity index $(D)$, and McIntosh's equitability $(E)$ were used to assess species richness, dominance and evenness in a microbial community, respectively (Wang et al., 2012b). The 144-h data were also used to compare the utilization of six categories of carbon sources by microorganisms during different time periods of decomposition.

\subsection{Statistical analysis}

Data are presented as means \pm standard deviation $(n=3)$. A two-way analysis of variance (ANOVA) was used to compare the group means using SPSS 18.0 (SPSS Inc., Chicago, USA). Pairwise comparison of means was conducted using Duncan's multiple range test. Pearson's correlation analysis was conducted among straw residual rate, straw and soil properties, and microbial diversity to identify the key factor(s) affecting the rate of straw decomposition in the orchard soil using Excel 2016 (Microsoft Corp., Redmond, USA).

\section{Results}

\subsection{Changes in straw residual rate, straw water content and soil conditions}

Based on the residual rate of fresh straw, we divided the entire process of straw decomposition into two stages (Fig. 1). The first stage $(0-10 \mathrm{~d})$ was characterized by a rapid decrease in straw residual rate, with the values of $\mathrm{FB}, \mathrm{FC}$ and $\mathrm{FCN}$ samples decreasing from $100.0 \%$ to $45.4 \%$, $30.4 \%$ and $34.4 \%$, respectively. The second stage (10-360 d) was characterized by a slow decrease in straw residual rate, with the values of FB, FC and FCN samples further decreasing to $30.3 \%, 19.0 \%$ and $22.9 \%$, respectively. As the decomposition process advanced, the residual rates of FB samples were the highest, followed by those of FCN and FC samples $(P<0.05)$. This result indicated that fresh bean straw with a lower $\mathrm{C} / \mathrm{N}$ ratio decomposed slower than did fresh corn straw with a higher $\mathrm{C} / \mathrm{N}$ ratio. 


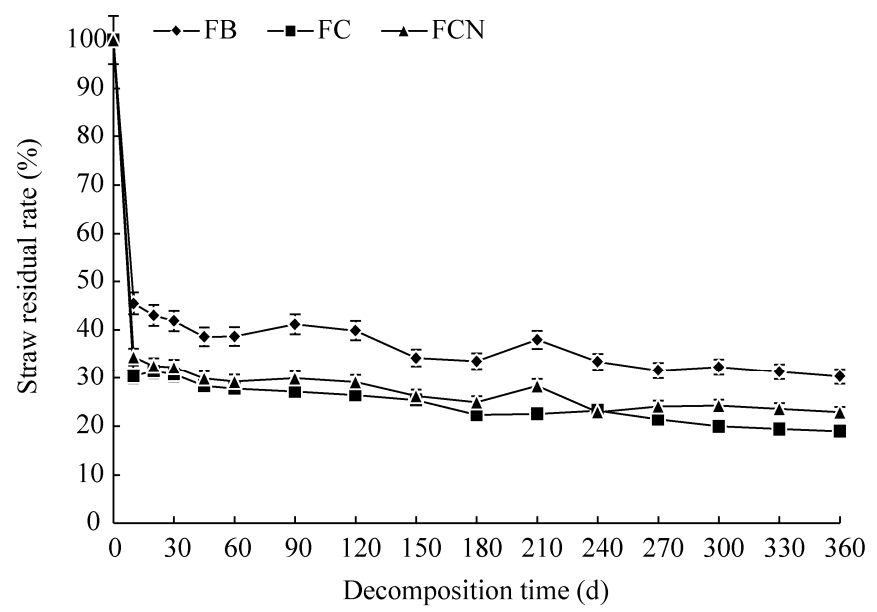

Fig. 1 Changes in straw residual rate in the soil of peach orchard during the decomposition process over a 360-d period. FB, fresh bean straw; FC, fresh corn straw; FCN, fresh corn straw+nitrogen fertilizer (urea, $10.34 \mathrm{~g} / \mathrm{kg}$ ). Bars are standard deviation $(n=3)$.

During the decomposition process, soil temperature considerably varied in an inverted S-shaped pattern, whereas soil water content had little change over time (Fig. 2). The water contents of all straw samples increased over time in the first 0-240 d but then decreased afterwards. The final water contents of soil and straw (FB, FC and FCN) samples at the end of the decomposition $(360 \mathrm{~d})$ increased by $107.9 \%, 112.8 \%, 157.0 \%$ and $162.3 \%$, respectively, compared with the initial values $(10 \mathrm{~d})$. This result indicated that straw water content had greater variations than soil water content over the entire process of straw decomposition.

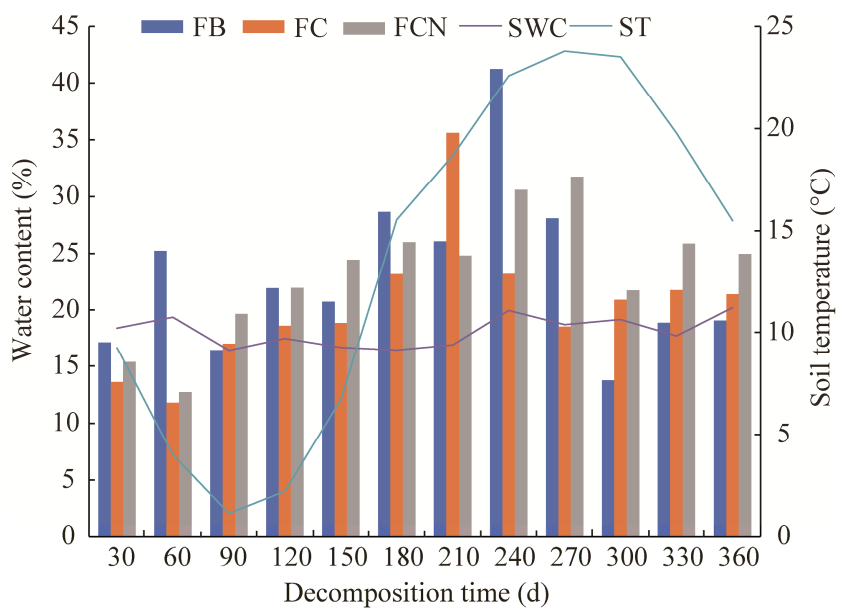

Fig. 2 Changes in straw water content (FB, FC and FCN), soil water content (SWC), and soil temperature (ST) in the peach orchard during the decomposition process over a 360-d period. FB, fresh bean straw; FC, fresh corn straw; FCN, fresh corn straw+nitrogen fertilizer (urea, $10.34 \mathrm{~g} / \mathrm{kg}$ ).

\subsection{Changes in microbial metabolic activity and functional diversity}

\subsubsection{Microbial metabolic activity}

With regard to microbial community metabolism, AWCD values of all straw samples changed with extended time periods of decomposition (Fig. 3). Generally, there were no significant differences in AWCD values among the three treatments; however, a relatively large difference emerged at $270 \mathrm{~d}$, which corresponded to a hot and rainy period with a high temperature. At this time, AWCD values of FCN samples were lower than those of the other two treatments. AWCD values of soil samples were relatively low $(<0.97)$ during the early stage $(0-90 \mathrm{~d})$, yet abruptly increased, peaking at 1.72 at $120 \mathrm{~d}$, followed by fluctuations between 1.55 and 1.06. Based on 
these results, FB samples exhibited higher microbial metabolic activities during the period of 0-240 d and gradually decreased during the period of 240-360 d. In contrast, microbial metabolic activities of FC samples were the lowest during the period of 0-240 d, and then increased to higher levels during the period of 240-360 d. For FCN samples, microbial metabolic activities were in the medium ranges.

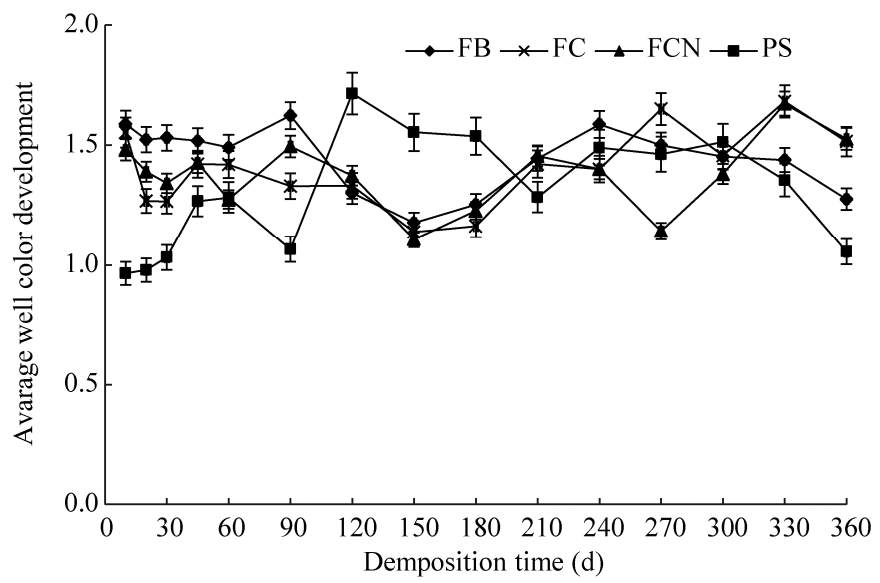

Fig. 3 Changes in average well color development associated with straw decomposition in the peach orchard over a 360-d period. FB, fresh bean straw; FC, fresh corn straw; FCN, fresh corn straw+nitrogen fertilizer; PS, soil of peach orchard. Bars are standard deviation $(n=3)$.

Final AWCD values of FB, FC and FCN samples decreased to $80.3 \%, 97.6 \%$ and $103.1 \%$ of their initial values, respectively, whereas those of soil samples increased to $109.4 \%$ of the initial values. Despite similar AWCD values among the three treatments, significant differences occurred across different time periods of decomposition $(P<0.01)$. There was a significant interactive effect between straw type and decomposition time $(P<0.01)$. Similarly, AWCD values of soil samples significantly differed across various time periods of decomposition $(P<0.01)$.

\subsubsection{Microbial functional diversity}

Table 1 summarizes the Shannon's diversity index $(H)$, Simpson's diversity index $(D)$, and McIntosh's equitability $(E)$ of straw-associated microbial communities under different treatments. In all cases, $H$ values did not change significantly over the entire decomposition period $(360 \mathrm{~d})$, and final $H$ values were only slightly changed to $101.7 \%$ (FB), $100.0 \%$ (FC), and $98.9 \%$ (FCN) of the initial values $(10 \mathrm{~d})$. Mean $H$ value of FB samples was significantly lower than those of FC and FCN samples $(P<0.05)$.

Table 1 Shannon's diversity index $(H)$, Simpson's diversity index $(D)$, and McIntosh's equitability $(E)$ of microbial communities associated with straw decomposition in the soil of peach orchard

\begin{tabular}{|c|c|c|c|c|c|c|c|c|c|}
\hline \multirow{2}{*}{$\begin{array}{l}\text { Decomposition } \\
\text { time (d) }\end{array}$} & \multicolumn{3}{|c|}{ FB } & \multicolumn{3}{|c|}{$\mathrm{FC}$} & \multicolumn{3}{|c|}{$\mathrm{FCN}$} \\
\hline & $H$ & $D$ & $E$ & $H$ & $D$ & $E$ & $H$ & $D$ & $E$ \\
\hline 10 & $3.524^{\mathrm{ab}}$ & $0.9612^{\mathrm{bc}}$ & $1.051^{\mathrm{b}}$ & $3.534^{\mathrm{ab}}$ & $0.9612^{\mathrm{ab}}$ & $1.081^{\mathrm{ab}}$ & $3.552^{\mathrm{ab}}$ & $0.9598^{\mathrm{b}}$ & $1.062^{\mathrm{ab}}$ \\
\hline 90 & $3.542^{\mathrm{ab}}$ & $0.9621^{\mathrm{b}}$ & $1.033^{\mathrm{b}}$ & $3.572^{\mathrm{ab}}$ & $0.9589^{\mathrm{b}}$ & $1.062^{\mathrm{ab}}$ & $3.640^{\mathrm{ab}}$ & $0.9649^{\mathrm{a}}$ & $1.074^{\mathrm{a}}$ \\
\hline 180 & $3.634^{\mathrm{a}}$ & $0.9585^{\mathrm{bc}}$ & $1.074^{\mathrm{b}}$ & $3.653^{\mathrm{a}}$ & $0.9594^{\mathrm{b}}$ & $1.104^{\mathrm{a}}$ & $3.653^{\mathrm{a}}$ & $0.9644^{\mathrm{a}}$ & $1.081^{\mathrm{a}}$ \\
\hline 270 & $3.473^{\mathrm{b}}$ & $0.9745^{\mathrm{a}}$ & $1.012^{\mathrm{c}}$ & $3.504^{\mathrm{ab}}$ & $0.9649^{\mathrm{a}}$ & $1.033^{\mathrm{ab}}$ & $3.612^{\mathrm{ab}}$ & $0.9599^{b}$ & $1.070^{\mathrm{ab}}$ \\
\hline 360 & $3.582^{\mathrm{ab}}$ & $0.9502^{d}$ & $1.084^{\mathrm{a}}$ & $3.534^{\mathrm{ab}}$ & $0.9528^{\mathrm{c}}$ & $1.030^{\mathrm{c}}$ & $3.513^{\mathrm{ab}}$ & $0.9593^{c}$ & $1.034^{\mathrm{ab}}$ \\
\hline Mean & $3.551^{\mathrm{B}}$ & $0.9613^{\mathrm{AB}}$ & $1.051^{\mathrm{B}}$ & $3.560^{\mathrm{A}}$ & $0.9594^{\mathrm{B}}$ & $1.062^{\mathrm{AB}}$ & $3.594^{\mathrm{A}}$ & $0.9617^{\mathrm{A}}$ & $1.064^{\mathrm{A}}$ \\
\hline
\end{tabular}

Note: FB, fresh bean straw; FC, fresh corn straw, FCN, fresh corn straw+nitrogen fertilizer. For each index, different lowercase letters within the same column indicate significant difference among various time periods of decomposition at $P<0.05$ level; different uppercase letters within the same row indicate significant difference among various straw treatments at $P<0.05$ level.

$D$ values varied from 0.9528 to 0.9745 , which showed significant differences across various time periods of straw decomposition $(P<0.05)$. In addition, there was a significant difference 
between mean $D$ values of FCN and FC samples $(P<0.05)$. These results indicated that the dominance of straw-associated microbial communities did not change much with the extension of decomposition time.

$E$ values showed similar changes as those observed in $H$ values. $E$ values of $\mathrm{FB}$ and $\mathrm{FC}$ samples significantly differed across various time periods of straw decomposition $(P<0.05)$, whereas the values of FCN samples did not change. Final $E$ values of FB samples increased to $102.9 \%$ of the initial values. In contrast, final values of FC and FCN samples decreased to $95.4 \%$ and $97.2 \%$ of their initial values, respectively. There was a significant difference between mean $E$ values of FB and FCN samples $(P<0.05)$.

\subsubsection{Carbon source utilization}

Based on the results of carbon source utilization (Table 2), there were no significant differences between the initial $(10 \mathrm{~d})$ and final $(360 \mathrm{~d})$ utilization rates of aromatic (FB, FC and FCN) and polymer (FB) in specific samples. However, utilization rates of most carbon source significantly increased in the later stage of straw decomposition compared with early stage $(P<0.05)$. Specifically, final utilization rates of amino acid significantly increased to $282.3 \%$ (FB), $346.8 \%$ (FC), and 365.2\% (FCN) of their initial values. Similar increases were found in the corresponding utilization rates of carboxylic acid, i.e., $285.1 \%, 312.5 \%$ and $344.2 \%$. In comparison, the increases in final utilization rates of saccharide were smaller, i.e., $216.9 \%, 274.6 \%$ and $301.6 \%$. For polyamine, final utilization rates increased to $247.5 \%, 286.4 \%$ and $400.0 \%$ of their initial values. Moreover, final utilization rates of polymer increased by $148.8 \%, 275.0 \%$ and $332.0 \%$ at the end of the decomposition process.

Table 2 Utilization of six categories of carbon source by microbial community in relation to the decomposition of various straw types at different time periods in the soil of peach orchard

\begin{tabular}{|c|c|c|c|c|c|c|c|}
\hline Straw type & $\begin{array}{l}\text { Decomposition } \\
\text { time (d) }\end{array}$ & Amino acid & $\begin{array}{l}\text { Carboxylic } \\
\text { acid }\end{array}$ & Saccharide & Polyamine & Polymer & Aromatic \\
\hline \multirow[t]{5}{*}{ FB } & 10 & $0.50^{\mathrm{e}}$ & $0.47^{\mathrm{e}}$ & $0.71^{\mathrm{e}}$ & $0.40^{\mathrm{d}}$ & $0.84^{\mathrm{d}}$ & $0.38^{\mathrm{d}}$ \\
\hline & 90 & $1.44^{\mathrm{b}}$ & $1.36^{\mathrm{a}}$ & $1.84^{\mathrm{a}}$ & $1.14^{\mathrm{b}}$ & $2.05^{\mathrm{a}}$ & $1.64^{\mathrm{a}}$ \\
\hline & 180 & $1.15^{\mathrm{d}}$ & $1.02^{\mathrm{cd}}$ & $1.49^{\mathrm{d}}$ & $0.88^{\mathrm{c}}$ & $1.39^{\mathrm{bc}}$ & $1.28^{\mathrm{ab}}$ \\
\hline & 270 & $1.80^{\mathrm{a}}$ & $1.30^{\mathrm{ab}}$ & $1.77^{\mathrm{ab}}$ & $1.53^{\mathrm{a}}$ & $1.09^{\mathrm{cd}}$ & $0.76^{\mathrm{bcd}}$ \\
\hline & 360 & $1.41^{\mathrm{bc}}$ & $1.34^{\mathrm{a}}$ & $1.54^{\mathrm{cd}}$ & $0.99^{\mathrm{bc}}$ & $1.25^{\mathrm{cd}}$ & $0.75^{\mathrm{cd}}$ \\
\hline \multirow[t]{5}{*}{$\mathrm{FC}$} & 10 & $0.47^{\mathrm{d}}$ & $0.48^{\mathrm{e}}$ & $0.67^{\mathrm{e}}$ & $0.44^{\mathrm{d}}$ & $0.60^{\mathrm{d}}$ & $0.43^{\mathrm{c}}$ \\
\hline & 90 & $1.14^{\mathrm{bc}}$ & $1.13^{\mathrm{c}}$ & $1.66^{\mathrm{bc}}$ & $0.87^{\mathrm{c}}$ & $1.53^{\mathrm{abc}}$ & $1.03^{\mathrm{abc}}$ \\
\hline & 180 & $1.26^{\mathrm{bc}}$ & $0.95^{\mathrm{d}}$ & $1.22^{\mathrm{d}}$ & $0.97^{\mathrm{bc}}$ & $1.28^{\mathrm{bc}}$ & $1.28^{\mathrm{ab}}$ \\
\hline & 270 & $1.86^{\mathrm{a}}$ & $1.36^{\mathrm{ab}}$ & $1.70^{\mathrm{ab}}$ & $1.43^{\mathrm{a}}$ & $1.86^{\mathrm{a}}$ & $1.59^{\mathrm{a}}$ \\
\hline & 360 & $1.63^{\mathrm{a}}$ & $1.50^{\mathrm{a}}$ & $1.84^{\mathrm{a}}$ & $1.26^{\mathrm{ab}}$ & $1.65^{\mathrm{ab}}$ & $0.78^{\mathrm{bc}}$ \\
\hline \multirow[t]{5}{*}{$\mathrm{FCN}$} & 10 & $0.46^{\mathrm{e}}$ & $0.43^{\mathrm{e}}$ & $0.61^{\mathrm{e}}$ & $0.31^{\mathrm{e}}$ & $0.50^{\mathrm{c}}$ & $0.26^{\mathrm{b}}$ \\
\hline & 90 & $1.39^{\mathrm{b}}$ & $1.23^{\mathrm{b}}$ & $1.82^{\mathrm{ab}}$ & $0.95^{\mathrm{b}}$ & $1.70^{\mathrm{a}}$ & $1.26^{\mathrm{a}}$ \\
\hline & 180 & $1.24^{\mathrm{bcd}}$ & $0.93^{\text {cd }}$ & $1.45^{\mathrm{cd}}$ & $0.90^{\mathrm{bc}}$ & $1.25^{\mathrm{ab}}$ & $1.41^{\mathrm{a}}$ \\
\hline & 270 & $1.42^{\mathrm{b}}$ & $1.09^{\mathrm{bc}}$ & $1.28^{\mathrm{d}}$ & $0.64^{\text {cd }}$ & $1.06^{\mathrm{b}}$ & $0.46^{\mathrm{b}}$ \\
\hline & 360 & $1.68^{\mathrm{a}}$ & $1.48^{\mathrm{a}}$ & $1.84^{\mathrm{a}}$ & $1.24^{\mathrm{a}}$ & $1.66^{\mathrm{a}}$ & $0.55^{\mathrm{b}}$ \\
\hline
\end{tabular}

Note: FB, fresh bean straw; FC, fresh corn straw, FCN, fresh corn straw and nitrogen. In each straw treatment, different lowercase letters within the same column mean significant difference across various decomposition time periods at $P<0.05$ level.

Based on the overall utilization of different carbon sources, we found that microorganisms associated with straw decomposition in the soil of peach orchard were dominated by saccharide-metabolizing group. Among the six categories of carbon source tested, microbial utilization of polymer ranked the lowest in FB samples, while that of aromatic was the lowest in FC and FCN samples.

\subsection{Relationships of soil/straw properties and microbial diversity with straw residual rate}

Across all three treatments, straw residual rate was negatively correlated with soil available phosphorus, soil available potassium and soil temperature $(P<0.01$; Table 3$)$. For FC and FCN 
samples, straw residual rate was also negatively correlated with straw water content and amino acid $(P<0.05$ or 0.01$)$ and positively correlated with $H$ value $(P<0.01)$. Moreover, straw residual rate of FC was negatively correlated with carboxylic acid utilization $(P<0.05)$, whereas straw residual rate of FCN was positively correlated with $E$ value $(P<0.05)$. These results indicated that the relationships of straw/soil properties and straw-associated microbial diversity with straw residual rate varied and depended on the straw type. Overall, there were more correlated variables in corn straw (FC and FCN) than in bean straw (FB).

Table 3 Pearson's correlations of straw/soil properties and microbial functional diversity with straw residual rate under different straw treatments

\begin{tabular}{|c|c|c|c|c|c|c|c|}
\hline \multirow{2}{*}{ Variable } & \multicolumn{3}{|c|}{ Straw residual rate } & \multirow{2}{*}{ Variable } & \multicolumn{3}{|c|}{ Straw residual rate } \\
\hline & FB & $\mathrm{FC}$ & FCN & & FB & $\mathrm{FC}$ & $\mathrm{FCN}$ \\
\hline $\mathrm{pH}$ & 0.20 & 0.30 & 0.26 & Saccharide utilization & -0.11 & -0.21 & -0.49 \\
\hline $\mathrm{OM}$ & 0.23 & 0.38 & 0.33 & Amino acid utilization & -0.43 & $-0.59^{*}$ & $-0.62^{*}$ \\
\hline $\begin{array}{c}\text { Alkali-hydrolyzable } \\
\text { nitrogen }\end{array}$ & 0.20 & 0.34 & 0.21 & $\begin{array}{l}\text { Carboxylic acid } \\
\text { utilization }\end{array}$ & -0.30 & $-0.58^{*}$ & -0.48 \\
\hline Available phosphorus & $-0.79^{* *}$ & $-0.83^{* *}$ & $-0.81^{* *}$ & Polymer utilization & 0.19 & -0.13 & -0.33 \\
\hline Available potassium & $-0.67^{* *}$ & $-0.69^{* *}$ & $-0.67^{* *}$ & Aromatic utilization & -0.10 & 0.42 & -0.22 \\
\hline Soil temperature & $-0.74^{* *}$ & $-0.76^{* *}$ & $-0.74^{* *}$ & Polyamine utilization & -0.41 & -0.24 & -0.41 \\
\hline Straw water content & -0.29 & $-0.63^{*}$ & $-0.81^{* *}$ & Shannon's diversity index $(H)$ & -0.40 & $0.68^{* *}$ & $0.75^{* *}$ \\
\hline Soil water content & -0.37 & -0.24 & -0.39 & Simpson's diversity index $(D)$ & 0.00 & 0.00 & 0.00 \\
\hline AWCD & -0.38 & -0.44 & 0.04 & McIntosh's equitability $(E)$ & -0.50 & 0.00 & $0.59^{*}$ \\
\hline
\end{tabular}

Notes: FC, fresh corn straw; FB, fresh bean straw; FCN, fresh corn straw and nitrogen; OM, organic matter; AWCD, average well color development. ${ }^{*}, P<0.05$ level, ${ }^{* *}, P<0.01$ level.

\section{Discussion}

\subsection{Effect of $\mathrm{C} / \mathrm{N}$ ratio on straw decomposition}

Decomposition rate of organic materials applied to soil depends on both their inherent properties and ambient conditions (Kuang et al., 2010). There is much evidence that $\mathrm{C} / \mathrm{N}$ ratio of organic materials is a major factor controlling their decomposition and nutrient release. For example, Cheng et al. (2014) found that a $\mathrm{C} / \mathrm{N}$ ratio of corn straw controls nitrogen release from the straw and affects microbial activity in the soil. In the present study, we applied three types of fresh crop straw to the soil of peach orchard and closely monitored their decomposition over a 360-d period. $\mathrm{C} / \mathrm{N}$ ratios of different straw samples were ranked in the following order: $\mathrm{FC}>\mathrm{FCN}>\mathrm{FB}$, which corresponded to their decomposition rates over a 360-d incubation period. This result indicates that corn straw having a higher $\mathrm{C} / \mathrm{N}$ ratio was easier to decompose than bean straw having a lower $\mathrm{C} / \mathrm{N}$ ratio in the soil of peach orchard, which corroborates our recently reported findings in a farmland soil (Zhang et al., 2019). This phenomenon may be explained by the fact that the $\mathrm{C} / \mathrm{N}$ ratio of soil in the peach orchard was approximately 14.73, quite close to that of bean straw (14.65) and much lower than that of corn straw with (25.00) or without (35.59) nitrogen fertilizer. Therefore, corn straw was more likely to compete for nitrogen in this soil than bean straw, thereby accelerating straw decomposition by local soil microorganisms in its vicinity.

A positive relationship between straw decomposition rate and $\mathrm{C} / \mathrm{N}$ ratio indicates that an optimal $\mathrm{C} / \mathrm{N}$ ratio of crop straw is not necessary for accelerating straw decomposition in the soil. For example, although $\mathrm{FC}$ straw had a considerably high $\mathrm{C} / \mathrm{N}$ ratio, its $\mathrm{C}$ and $\mathrm{N}$ nutrition could be balanced through the ambient soil environment over a certain period of time, eventually facilitating straw decomposition. When urea was supplied as a nitrogen source, FCN straw attained an optimal $\mathrm{C} / \mathrm{N}$ ratio for microbial decomposition. However, according to Li et al. (2017), the addition of urea could inhibit ligninase activity in corn straw and thus impair the straw decomposition process. A similar result was reported by Wang and Sun (2012a), who applied wheat straw to a sandy soil. Moreover, $\mathrm{FB}$ straw had a $\mathrm{C} / \mathrm{N}$ ratio close to that of the soil in peach 
orchard with slowly releasing carbon and nitrogen during decomposition, especially under limited soil water conditions. In this case, it took a longer time for FB straw to influence microbial community in the vicinity and to stimulate microbial activity associated with straw decomposition. Therefore, among the three treatments, FB had the lowest straw decomposition rate throughout the experimental period.

\subsection{Effects of soil temperature and water conditions on straw decomposition}

Previous studies have found that functional diversity of microbial communities associated with straw decomposition is affected by environmental conditions, such as soil temperature and humidity (Villegas et al., 2000; Avrahami et al., 2003; Kruse et al., 2004). Soil temperature and water content mainly affect the growth, reproduction and physiological functions of particular microbial groups. In addition, these factors affect the soluble organic matter content of soil and the decomposition rate of straw; thus, differences arise in substrate supply, leading to shifts in the activity and function of soil microbial communities (Avrahami et al., 2003; Tian et al., 2007). Most soil microorganisms have an optimal temperature between $25^{\circ} \mathrm{C}$ and $35^{\circ} \mathrm{C}$, so the degradation and nutrient transformation of crop residues are relatively fast in the tropics (Ding et al., 2008). In hot and humid environments, soil microbial activity is enhanced and nutrients in straw can be released quickly. In the present study, we found that there was a negative correlation between soil temperature and straw residual rate across different straw treatments. However, the decomposition rates of different straws tended to decline in the middle and late stages when soil temperature was relatively high in the peach orchard. This result indicates that the decomposition process of different straws was not only affected by soil temperature, but also related to other factors. For example, we found that straw water content was negatively correlated with the residual rate of corn straw with or without nitrogen fertilizer.

In our study area, soil temperature mainly changed with seasonal air temperature, whereas straw water content was related to straw physical structure, soil water content and seasonal precipitation. The negative correlation observed between residual rate and water content of corn straw may be due to the fact that corn straw contains more water-soluble substances and crude proteins that are easy to decompose. Under appropriate temperature and water conditions, the production and turnover of extracellular enzymes by soil microorganisms can indirectly mediate the decomposition of organic matter, thus reducing the residual rate of corn straw in the soil of peach orchard. Similar results have been reported by Tian et al. (2020) in a fluvo-aquic soil and Cusack et al. (2010) in two tropical soils. However, there was no correlation between the residual rate and water content of soybean straw, perhaps because soybean straw contains high cellulose, hemicellulose and lignin contents, which may not facilitate the decomposition process in the presence of high water content. Compared with corn straw, the decomposition of soybean straw requires more energy, which reduces the extent of straw decomposition by microorganisms; thus, little change occurred in the residual rate of soybean straw during the whole decomposition period. This mechanism is consistent with the finding of Ibrahim et al. (2015) in a paddy soil.

In the present study, we found that soil water content had minor effect on the decomposition rates of different fresh straws, while straw water content partially affected the decomposition rates. A plausible reason was that water treatment in our study did not reach the soil water limit, so its effect on microbial activity was not significant (Zhou et al., 2015). Our finding contradicts several earlier studies, such as Castro et al. (2010) and Sun et al. (2018), which involved the application of corn straw to the soil of apple orchards. Zhang et al. (2007) also found that water conditions could affect the physical and chemical properties of soil, causing differences in the decomposition rate of various crop residues in a purple paddy soil. The inconsistency between the current and previous studies may be due to the presence of multiple factors (e.g., straw type and soil environment) influencing straw decomposition in the fields. For example, Neilson et al. (2012) showed that the change of environmental conditions could considerably affect the microbial community composition. More recently, Tian et al. (2020) demonstrated that both straw type and soil texture affected the decomposition of straw, and difference in the nutrient conditions of 
residual straw was the primary cause of variation in microbial abundance and community composition.

In summary, our results indicate that the decomposition rates of fresh straws are strongly affected by soil temperature across different treatments. Therefore, straw decomposition mediated by microorganisms is more sensitive to temperature than to water in the soil of peach orchard.

\subsection{Effect of microbial community structure on straw decomposition}

To monitor dynamic changes in straw-associated microbial communities during the decomposition process, we used Biolog-Eco microplate assay to analyze the microbial metabolic activity and carbon source utilization. With increasing decomposition time, the higher AWCD values of FC and FCN samples indicated that their microbial metabolic activities associated with straw decomposition were enhanced and became stable, which could promote straw decomposition. Consequently, residual rate of corn straw was lower than that of soybean straw. As the decomposition process advanced, the amount of easily decomposed substances decreased, and complex compounds that are difficult to decompose accumulated gradually. In agreement with our finding, previous studies showed that microbial activity associated with the transformation of complex compounds in crop straws was reduced after decomposition under good hydrothermal conditions; thus, AWCD values decreased with increasing soil temperature and water content (Kemmitt et al., 2008; Wang et al., 2012b).

Regarding microbial functional diversity, we observed higher $H$ values from FC and FCN samples compared with FB samples after straw decomposition, whereas for $E$ values, this trend was inversed (i.e., FC and FCN $<$ FB). During field sampling, we found a high abundance of nematodes (average density: 1280/100 g dry soil) in the soil of peach orchard, which could be attributed to the occurrence of abundant fungi. According to Zhang et al. (2018), nitrogen addition in grassland soil could reduce the species evenness of nematodes and alter their species richness, thereby influencing the stability of nematode community. This leads us to speculate that the nematodes around mesh bags of corn straw with low nitrogen were more active during straw decomposition than those around mesh bags of bean straw with high nitrogen. Since fungi are the main decomposers of soil and straw organic compounds, they were likely to decrease the species evenness of microbial communities associated with corn straw decomposition.

Saccharides are easy to decompose and they can be produced in secondary metabolites when crop straw is decomposed and then utilized by microorganisms (Wang et al., 2009). Under different treatments, we found that dominant microorganisms associated with straw decomposition mainly fed on saccharides. In addition, saccharides were sensitive carbon sources causing microbial community shifts among various straw treatments in the soil of peach orchard. In contrast, microorganisms in FB samples had the lowest utilization rate of polymer, which could easily reduce the stability of microbial community structure (Zhen et al., 2015) and negatively affect the decomposition of crop straw. FC and FCN samples had the lowest utilization rates of aromatic by microorganisms, which are similar to the result obtained from Caragana microphylla and other plant residues applied to a forest soil (Zhang et al., 2009). Based on these results, polymer and aromatic appeared to be the key components that restricted the decomposition rates of bean straw and corn straw in the soil of peach orchard during the later stage of the decomposition process. Therefore, it is crucial to effectively treat crop straw in order to make full use of various carbon resources throughout the decomposition process.

\section{Conclusions}

This study demonstrated that fresh corn straw decomposed faster than fresh soybean straw in the soil of peach orchard over the 360-d incubation. With the extension of decomposition time, the microbial metabolic activity associated with corn straw decomposition increased, while the microbial community structure became increasingly stable. Especially under hot and humid conditions, straw-associated microbial communities had the greatest differences across various treatments in the middle and late stages of decomposition. Genetic fingerprinting techniques, such 
as T-RFLP (terminal-restriction fragment length polymorphism) and PCR-DGGE (polymerase chain reaction-denaturing gradient gel electrophoresis) are needed to explore the differential utilization of carbon sources by microorganisms during straw decomposition. Across different treatments, the dominant microorganisms associated with straw decomposition were mainly carbohydrate-utilizing groups. In the middle and late stages, the decomposition rate of straw was markedly reduced due to gradual accumulation of polymer (soybean straw) and aromatic (corn straw). When applying crop straw to the soil of orchard, $\mathrm{C} / \mathrm{N}$ ratio of straw should be adjusted to facilitate the decomposition process and improve the utilization rate of straw. In addition, microbial agents could be screened and applied to facilitate the degradation of polymer and aromatic during the middle and late stages. This strategy will ameliorate the utilization of straw resources after their field application, ultimately improving soil organic matter content and stabilizing the orchard soil quality.

\section{Acknowledgements}

This research was supported by the Project of State Key Laboratory of Soil Erosion and Dryland Farming on Loess Plateau, Chinese Academy of Sciences (A314021402-1916), the Key Project of the Ministry of Science and Technology of China (2017YFD0200200), and the Innovative Engineering Project of Shaanxi Province, China (2016slkj-15). We thank Dr. GU Jie, Dr. SUN Wei, Dr. QIAN Xun and Mr. ZHANG Youwang from College of Resources and Environmental Sciences, Northwest A\&F University, China for sample testing and analysis.

\section{References}

Avrahami S, Liesack W, Conrad R. 2003. Effects of temperature and fertilizer on activity and community structure of soil ammonia oxidizers. Environmental Microbiology, 5(8): 691-705.

Bao S D. 2007. Soil Agrochemical Analysis ( $3^{\text {rd }}$ ed.). Beijing: Chinese Agriculture Press, 30-113. (in Chinese)

Baumannn K, Marschner P, Smernik R J, et al. 2009. Residue chemistry and microbial community structure during decomposition of eucalypt, wheat and vetch residues. Soil Biology \& Biochemistry, 41(9): 1966-1975.

Cao Y F, Zhang H, Liu K, et al. 2015. Organic acids variation in plant residues and soils among agricultural treatments. Agronomy Journal, 107(6): 2171-2180.

Castro H F, Classen A T, Austin E E, et al. 2010. Soil microbial community responses to multiple experimental climate change drivers. Applied and Environmental Microbiology, 76: 999-1007.

Chang Q R, Yan X, Lei M, et al. 2001. The discussion on Lou soil position in soil classification. Journal of Northwest A\&F University (Natural Science Edition), 29(3): 48-52. (in Chinese)

Chen L, Zhang J B, Zhao B Z, et al. 2014. Carbon mineralization and microbial attributes in straw-amended soils as affected by moisture levels. Pedosphere, 24(2): 167-177.

Chen Q H, Feng Y, Zhang Y P, et al. 2012. Short-term responses of nitrogen mineralization and microbial community to moisture regimes in greenhouse vegetable soils. Pedosphere, 22: 263-272.

Chen R R, Senbayram M, Blagodatsky S, et al. 2014. Soil C and N availability determine the priming effect: microbial N mining and stoichiometric decomposition theories. Global Change Biology, 20(7): 2356-2367.

Chen X F, Li Z P, Liu M, et al. 2015. Microbial community and functional diversity associated with different aggregate fractions of a paddy soil fertilized with organic manure and/or NPK fertilizer for 20 years. Journal of Soils and Sediments, 15(2): 292-301.

Cheng C G, Zhao D Y, Lv D G, et al. 2014. Effects of plant-derived organic materials and humification driving forces on soil microbial community diversity in orchards. Journal of Plant Nutrition and Fertilizer, 20(4): 913-922. (in Chinese)

Cusack D F, Torn M S, Mcdowell W H, et al. 2010. The response of heterotrophic activity and carbon cycling to nitrogen additions and warming in two tropical soils. Global Change Biology, 16(9): 2555-2572.

Ding X L, He H B, Bai Z, et al. 2008. Fate and utilization of crop residues and their effect on soil nitrogen turnover. Chinese Journal of Soil Science, 39(6): 1454-1461. (in Chinese)

Feng X, Simpson M J. 2009. Temperature and substrate controls on microbial phospholipid fatty acid composition during incubation of grassland soils contrasting in organic matter quality. Soil Biology and Biochemistry, 41(4): 804-812.

Geisseler D, Horwath W R, Scow K M. 2011. Soil moisture and plant residue addition interact in their effect on extracellular enzyme activity. Pedobiologia, 54(2): 71-78.

Guo J F, Yang Y S, Chen G S, et al. 2006. A review on litter decomposition in forest ecosystem. Scientia Silvae Sinicae, 42(4): 
93-100. (in Chinese)

Han J Z, Kuang E J, Chi F Q, et al. 2016. Effects of different depths of straw returned to soil on biological characteristics. Chinese Journal of Soil Science, 47(5): 1154-1161. (in Chinese)

Hoyle F C, Murphy D V, Brookes P C. 2008, Microbial response to the addition of glucose in low-fertility soils. Biology Fertility of Soils, 44: 571-579.

Ibrahim M, Cao C G, Zhan M, et al. 2015. Changes of $\mathrm{CO}_{2}$ emission and labile organic carbon as influenced by rice straw and different water regimes. International Journal of Environmental Science and Technology, 12(1): 263-274.

Jia J X, Li Z P, Che Y P. 2010. Effects of glucose addition on N transformations in paddy soils with a gradient of organic C content in subtropical China. Scientia Agricultura Sinica, 43(8): 1617-1624. (in Chinese)

Jia X, Dong S M, Luo C J. 2013. Effects of Biolog Eco-plates incubation time on analysis results in microbial ecology researches. Journal of Basic Science and Engineering, 21(1): 10-19. (in Chinese)

Ju X T, Liu X J, Zhang F S. 2002. Nitrogen transformation and fate in soil under the conditions of mixed application of urea with DCD or different organic material. Scientia Agricultura Sinica, 35(2): 181-186. (in Chinese)

Kemmit S J, Lanyon C V, Waite I S, et al. 2008. Mineralization of native soil organic matter is not regulated by the size, activity or composition of the soil microbial biomass-A new perspective. Soil Biology and Biochemistry, 40(1): 61-73.

Kruse J, Kisse D E, Cabrera M L. 2004. Effects of drying and rewetting on carbon and nitrogen mineralization in soils and incorporated residues. Nutrient Cycling Agroecosystems, 69: 247-256.

Kuang E J, Chi F Q, Zhang J M, et al. 2010. Decomposed regularity of organic materials under different condition in black soil. Chinese Agricultural Science Bulletin, 26(7): 152-155. (in Chinese)

Lao X R, Sun W H, Wang Z. 2003. Effect of matching use of straw and chemical fertilizer on soil fertility. Acta Pedologica Sinica, 40(4): 623-629. (in Chinese)

Li L J, Zhu-Barker X, Ye R Z, et al. 2018. Soil microbial biomass size and soil carbon influence the priming effect from carbon inputs depending on nitrogen availability. Soil Biology and Biochemistry, 119: 41-49.

Li X G, Jia B, Lv J T, et al. 2017. Nitrogen fertilization decreases the decomposition of soil organic matter and plant residues in planted soils. Soil Biology \& Biochemistry, 112: 47-55.

Li Z Q, Li D D, Ma L, et al. 2019. Effects of straw management and nitrogen application rate on soil organic matter fractions and microbial properties in North China Plain. Journal of Soils and Sediments, 19(2): 618-628.

Liu W, Pan N, Chen W. 2012. Effect of veterinary oxytetracy-cline on functional diversity of soil microbial community. Plant Soil and Environment, 58: 295-301.

Liu Y, Gao X H, Yao Y C. 2008. Research on nutrient effect of different botanical organic fertilizers on young pear plant (Pyrus pyrifolia (Burm. f.) Nakai) in sandy soil. Scientia Agricultura Sinica, 41(8): 2546-2553. (in Chinese)

Liu Y, Li M, Zheng J W, et al. 2014. Short-term responses of microbial community and functioning to experimental $\mathrm{CO}_{2}$ enrichment and warming in a Chinese paddy field. Soil Biology and Biochemistry, 77: 58-68.

Lu S B, Zhang Y J, Chen C R, et al. 2013. Analysis of functional differences between soil bacterial communities in three different types of forest soils based on Biolog fingerprint. Acta Pedologica Sinica, 50(3): 618-623. (in Chinese)

Merilä P, Malmivaara-Lämsä M, Spetz P, et al. 2010. Soil organic matter quality as a link between microbial community structure and vegetation composition along a successional gradient in a boreal forest. Applied Soil Ecology, 46(2): $259-267$.

Neilson J W, Quade J, Ortiz M, et al. 2012. Life at the hyperarid margin: novel bacterial diversity in arid soils of the Atacama Desert, Chile. Extremophiles, 16(3): 553-566.

Pausch J, Kuzyakov Y. 2012. Soil organic carbon decomposition from recently added and older sources estimated by $\delta^{13} \mathrm{C}$ values of $\mathrm{CO}_{2}$ and organic matter. Soil Biology and Biochemistry, 55: 40-47.

Qian X, Gu J, Sun W, et al. 2014. Changes in the soil nutrient levels, enzyme activities, microbial community function, and structure during apple orchard maturation. Applied Soil Ecology, 77: 18-25.

Song L, Hang S, Lu J W, et al. 2015. Study on characteristics of decomposing and nutrients releasing of different proportional mixture of rape straw and Chinese milk vetch in rice field. Soils and Fertilizers Sciences in China, 3: 100-104. (in Chinese)

Sun X Y, Zhang X, Zhang P, et al. 2018. Effects of temperature, moisture and organic material on organic carbon transformation and microbial community diversity of soil in apple orchard. Chinese Journal of Soil Science, 49(4): 822-833. (in Chinese)

Tian G, Olimah J A, Adeoye G O, et al. 2000. Regeneration of earthworm populations in a degraded soil by natural , planted fallows under humid tropical conditions. Soil Science Society of America Journal, 64(1): 222-228.

Tian G, Badejo M A, Okoh A I, et al. 2007. Effects of residue quality and climate on plant residue decomposition and nutrient release along the transect from humid forest to Sahel of West Africa. Biogeochemistry, 86(2): 217-229.

Tian S Y, Li H M, Chen J L et al., 2020. Differences of nutrient contents in residual wheat and maize straws and their relationship with microbial community composition in Fluvo-Aquic soil. Soils, 52(3): 1-9. (in Chinese) 
Villegas P G, Blair G J, Lefroy R. 2000. Measurement of decomposition and associated nutrient release from straw (Oryza sativa $\mathrm{L}$.) of different rice varieties using a perfusion system. Plant and Soil, 223: 1-11.

Wang J Y, Wang M L, Zhang F H. 2016. Soil microbial properties under typical halophytic vegetation communities in arid regions. Acta Ecologica Sinica, 36(8): 2363-2372. (in Chinese)

Wang X D, Chen X N, Wang C X, et al. 2009. Decomposition of corn stalk in cropland with different fertility. Transactions of the Chinese Society of Agricultural Engineering, 25(10): 252-257. (in Chinese)

Wang X Y, Sun B. 2012. Factors affecting change of microbial community during plant residue decomposition: A Review. Soils, 44(3): 353-359. (in Chinese)

Wang X Y, Jiang Y Q, Sui Y Y, et al. 2012. Changes of microbial communities during decomposition of wheat and maize straw: analysis by Biolog. Acta Pedologica Sinica, 49(5): 1003-1011. (in Chinese)

Witt C, Cassman K G, Olk D C, et al. 2000. Crop rotation and residue management effects on carbon sequestration, nitrogen cycling and productivity of irrigated rice systems. Plant and Soil, 225(1): 263-278.

Wu J S, Zhang J C, Qian J F, et al. 2013. Intercropping grasses improve soil organic carbon content and microbial community functional diversities in Chinese hickory stands. Transactions of the Chinese Society of Agricultural Engineering, 29(20): 111-117. (in Chinese)

Wu Y P, Peng Q A, Muhammad S, et al. 2014. Research progress of effect of straw returning on soil microorganism. Chinese Agricultural Science Bulletin, 30(29): 175-183. (in Chinese)

Zabinski C A, Gannon J E. 1997. Effects of recreational impacts on soil microbial communities. Environmental Management, 21(2): 233-238.

Zhang A L, Zhang J N, Hong J, et al. 2018. Characteristics and interaction of soil nematodes and microbial communities in Stipa grandis grassland. Acta Agrestia Sinica, 26(1): 77-84. (in Chinese)

Zhang H, Cao Y F, Xu W X, et al. 2019. Decomposition of plant straws and accompanying variation of microbial communities. Acta Pedologica Sinica, 56(6): 1482-1492. (in Chinese)

Zhang H H, Tang M, Chen H. 2009. Characterization of soil microbial community function and structure in rhizosphere of typical tree species and the meaning for environmental indication in the Loess Plateau. Environmental Science, 30(8): 2432-2437. (in Chinese)

Zhang W, Wang Z F, Wang H, et al. 2007. Organic carbon mineralization affected by water content and plant residues in purple paddy soil. Plant Nutrition \& Fertilizer Science, 13(6): 1013-1019. (in Chinese)

Zhen L S, Gu J, Hu T, et al. 2015. Microbial community structure and metabolic characteristics of oil-contaminated soil in the loess plateau. Acta Ecologica Sinica, 35(17): 5703-5710. (in Chinese)

Zhou G X, Chen L, Zhang C Z, et al. 2015. Effects of temperature and moisture on microbial community function responsible for straw decomposition. Soils, 47(5): 911-918. (in Chinese) 